\title{
New Design for Energy Saving Water Dispensers
}

\author{
Xiangyun Huang \\ North China Electric Power University, Beijing, China \\ Email: 951664100@qq.com
}

Received March 2015

\begin{abstract}
This article is in view of the existing water dispensers' repeated heating, large energy consumption and fresh water quality's problem, designed a new type energy saving water dispenser with the function of rapid cooling-or-heating. Anhydrous bravery structure is used in the water dispensers in drinking water flow process to cool or heat it, so as to ensure the water quality fresh. Among them, the application of semiconductor refrigeration technology achieved collecting heat and preheating the water [1], which is called the initial heating. Cooperating with the secondary heating of the electrothermal quartz heating tube, the water dispensers really realize the flowing liquid heating, bid farewell to the so-called thousand-times boiling water and improve the heat energy utilization greatly [2].
\end{abstract}

\section{Keywords}

Two-Stage Heating, Semiconductor Refrigeration Technology, No-Bile Structure, Flowing-Liquid-Heating Technology, Cooling-or-Heating Function

\section{Introduction}

With people's living standard rising high, water dispensers have become the necessary facilities of the families, hotels, offices and public places. Taking the current water dispensers as an example, firstly, the traditional water dispensers usually has the bile to put hot or cold water, after a long-time use, water bile will gradually deposited with filth and scale cause the secondary pollution of drinking water [3]. Second, bile in hot water uses the heating resistance wire, it takes several minutes to heat the water, which far can't meet the needs of people. But if we set the water dispenser in the insulation state, water will be repeated heating, waste of energy, and health; Third, the existing part of the cooling water machine also uses the semiconductor chip, but its work process not only consumes more electricity, but also increases the chance of the dust getting into the water cooler by air flow [4].

Therefore, it is very necessary to invent a more energy-saving, healthy and convenient new water dispenser.

\section{The Working Principle and Design}

Designed in this paper, the new energy saving water dispenser is based on Semiconductor refrigeration technology [5] and flowing-liquid heating technology, which puts forward the heat handling and two-stage heating 
concept. Compared with the traditional water machine, it is obviously more energy saving and healthy.

Semiconductor refrigeration technology is based on semiconductor materials composed of P-N junction, formation of thermocouple, which produce the Pal effect for semiconductor chip. That is, after the semiconductor chip get into the dc power supply, it will absorb heat at one end of the joint, the other end will release quantity of heat, heat size is determined by the current.

Parr post effect of physics principle is: the current charge carriers in different materials are in different levels, when it moves from high level to low level, then release the excess energy. On the contrary, when the carrier from low level to high level, it will absorb energy from the outside world. Semiconductor refrigeration is a heat transfer tool. As long as the temperature of the cooling object is higher than the cold ends of semiconductor refrigeration piece, heat will be absorbed from the cold end and released in the hot end [6].

Semiconductor electrothermal film uses the insulator with excellent resistance of high temperature, high strength as the matrix, using a special process (temperature $800^{\circ} \mathrm{C}-1000^{\circ} \mathrm{C}$ ) on the substrate coating to prepare the inorganic materials. The conductive film made of the mixture, can work under $400^{\circ} \mathrm{C}$. The electrothermal has the characteristics of quick-start, large heat-transfer area, high stability, high efficiency of electric power con- version (95\%), so using it as a heating device has obvious energy saving effect.

\section{Common Computing Task of the Pow}

Assume that the room temperature environment, cold water and hot water flow process is timely $25^{\circ} \mathrm{C}$. regardless of the water in the process of the flow due to the temperature of the system inertia, lower water temperature of or falling). We selected the refrigeration power is $2 * 134+5 * 54.1=538.5 \mathrm{~W}$ of refrigeration, heating module is $2000 \mathrm{~W}$. Because the change of constant pressure heat capacity of water in the heating range is not big, taking $C_{p}=4174 \mathrm{~J} / \mathrm{kg}$. Now assume that $250 \mathrm{ml}$ of water counted by the discharge positioning flows over in 25 seconds.

The cold water valve of the water temperature:

$$
\mathrm{t}_{\text {cold }}=25-\frac{P T}{\rho v_{C_{p}}}=25-\frac{538.5 * 25}{1000 * 250 * 10^{-6} * 4174}=12.1^{\circ} \mathrm{C}
$$

Semiconductor wafers in cold end surface absorption heat and the heat generated by the work itself is transferred to the hot face, so that the level of the water in the radiator (about 2 liters) temperature rises to:

$$
t_{\text {hot }}=25+\frac{(538.5+12 * 6 * 5+12 * 15 * 2) * 25}{1000 * 2000 * 10^{-6} * 4174}=28.8^{\circ} \mathrm{C}
$$

Thus, the water temperature of the hot water valve as follows:

$$
\mathrm{t}_{\text {hot }}^{\prime}=28.8+\frac{P^{*} T}{\rho^{*} v^{*} c_{p}}=28.8+\frac{2000 * 25}{1000 * 250 * 10^{-6} * 4174}=76.7^{\circ} \mathrm{C}
$$

At this point, the temperature of the hot water valve is appropriate, so it can be drink directly. It is proved that the parameters of this work are set with rationality.

\section{Water Structure in Water Dispensers}

Drinking water from escaping from the barrels are divided into two after the road, all the way through the semiconductor refrigeration piece of cold ends, achieve rapid refrigeration; In addition all the way water flows through the first semiconductor refrigeration piece of hot end, for the semiconductor refrigeration piece of cooling at the same time, the implementation level of preheating, then flows through the electrothermal heating tube, realizes the secondary heating, become the hot water.

Water diagram of water dispenser in Figure 2.

As shown in Figure 1, the semiconductor refrigeration piece of hot end is with ribbed, cold section and heat exchanger fit closely to increase heat exchange area. To the left of the device for cold water, the direction of flow is from top to bottom, its external is also equipped with plastic foam thermal insulation layer, decreasing water heat exchange with the outside world at the same time. It also makes the fin in a cold environment and easy to work. Warm water warehouse is on the right and its direction of flow is from bottom to top (the density 
of hot water is less than cold water, therefore be in the upper part) held in device, aiming at cooling the working semiconductor chip Table 1, preheating the water at the same time.

The cooling structure Figures 2-4 including: heat exchanger, semiconductor chip, radiator element, cooling water tank and auxiliary cooling fan, etc. Both sides of the heat exchanger with copper, set inside have waterways. At work, drinking water gets through the heat exchanger, semiconductor chip transfers heat from the water to heat the casing, so as to achieve the effect of refrigeration.

\section{Summary}

This article is in view of problem of the existing water dispensers, repeated heating, large energy consumption

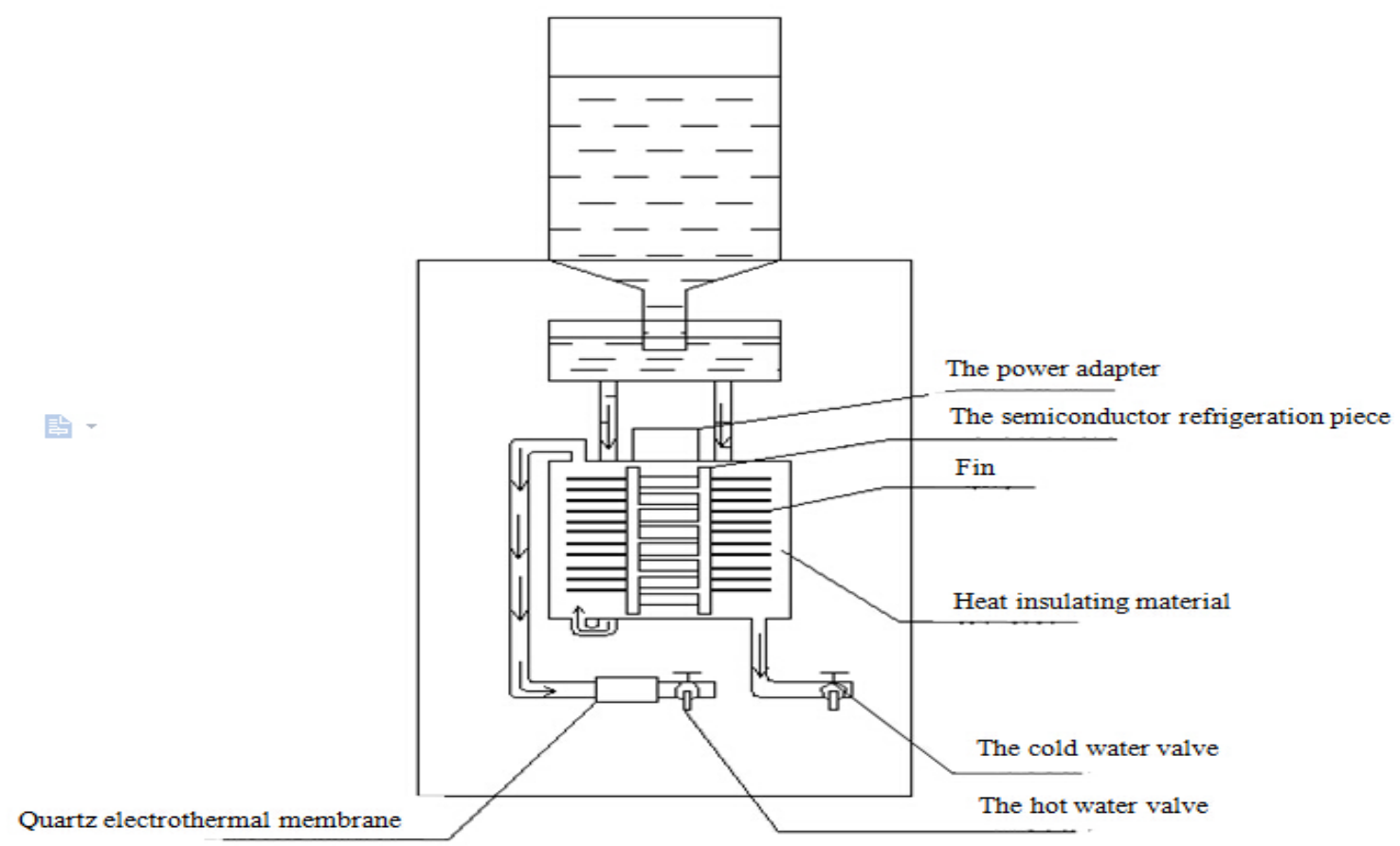

Figure 1. Water diagram.

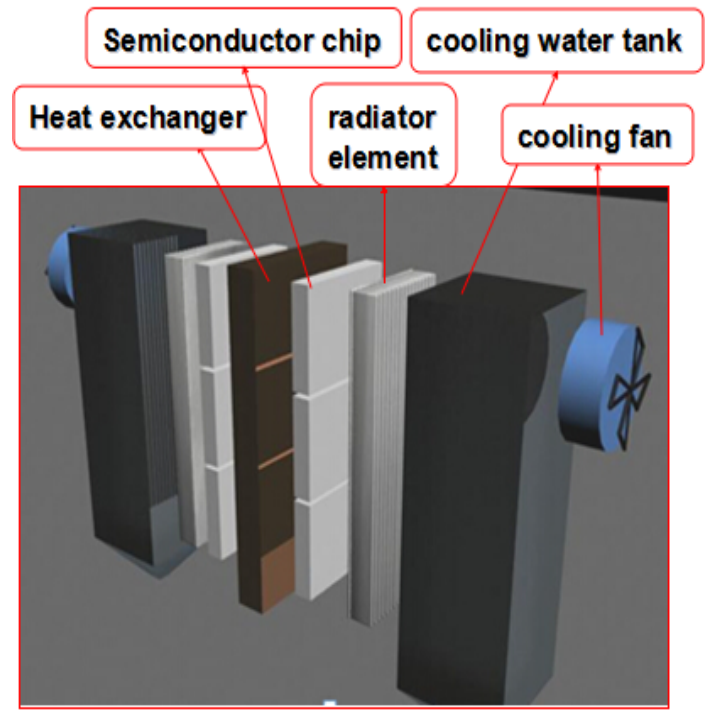

Figure 2. Cooling structure. 


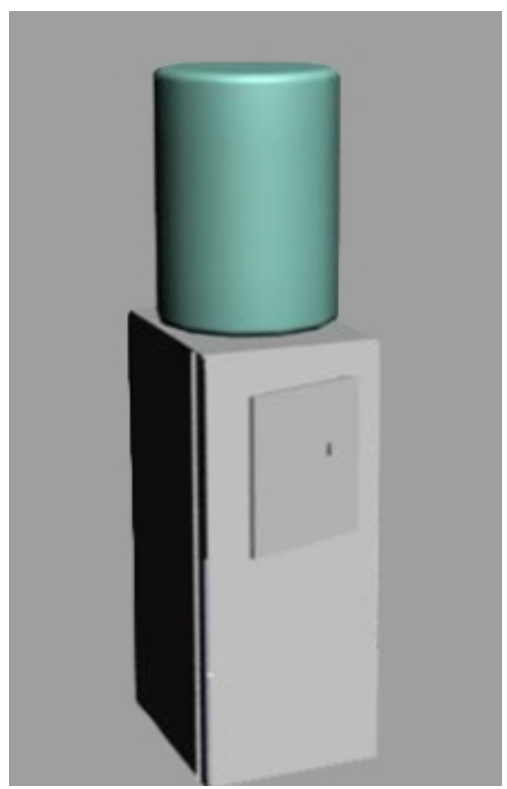

Figure 3. Inside structure.

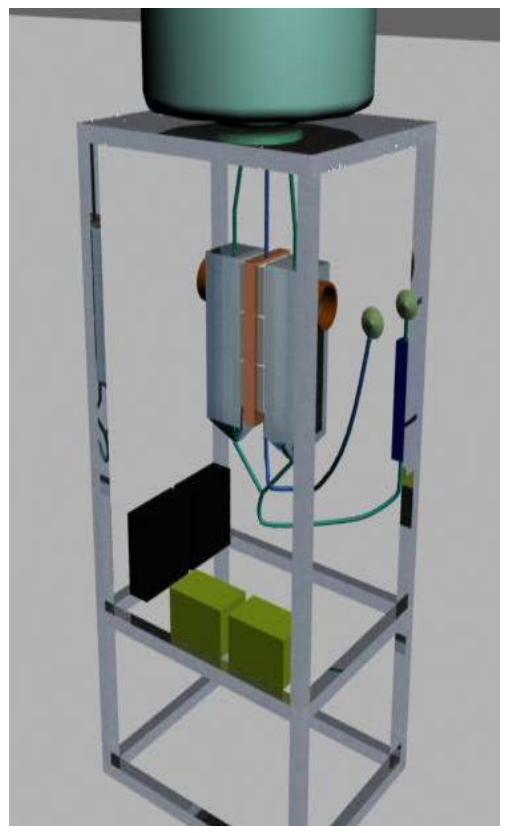

Figure 4. Outside view.

Table 1. The semiconductor chip working parameters.

\begin{tabular}{ccccc}
\hline $\begin{array}{c}\text { Refrigeration piece } \\
\text { type }\end{array}$ & $\begin{array}{c}\text { Maximum working } \\
\text { current }\end{array}$ & $\begin{array}{c}\text { Maximum working } \\
\text { voltage }\end{array}$ & $\begin{array}{c}\text { Maximum refrigeration } \\
\text { power }\end{array}$ & $\begin{array}{c}\text { Achievable maximum } \\
\text { temperature difference }\end{array}$ \\
\hline TEC1-12706 & $6 \mathrm{~A}$ & $12 \mathrm{~V}$ & $54.1 \mathrm{w}$ & $67^{\circ} \mathrm{C}$ \\
TEC1-12715 & 15 & 12 & 134 & $65^{\circ} \mathrm{C}$ \\
\hline
\end{tabular}

of fresh water quality's, designed a new type of energy saving water dispensers with the function of rapid coolingor-heating. This water machine adopts the structure without bile, which is not easy to accumulate dust and bacteria and be beneficial to the user's health. 
This work has good energy saving effect. Such a water machine can not only be installed in the home, but also in the station, parks and other public places. Serving the public and saving electric energy. The water dispenser can rapidly cool or heat the water, which meets the needs of different people on the water temperature, therefore has good application.

\section{References}

[1] Liu, Y.-F., Gao, Z.Y. and Liang, X.J. (2013) Heat Transfer. North China Electric Power University, August.

[2] Discharge Standard of Atmospheric Pollutants from Coal-Fired Power Plants (GB 13223-2011).

[3] Xiong, S.-Z. and Zhu, M.-F. (2009) Fundamentals and Applications of Solar Energy. Science Press, October.

[4] Wen, J.P., Li, H.-M., Cao, Y.H., et al. (2007) Design and Analysis of Energy Saving Water Machine. Yanshan University Institute of Mechanical Engineering, Technology Innovation Laboratory.

[5] Wang, G.C., Meng, X.-L. and Zhu, S. (2011) New Energy Saving Water Dispenser Design. Business Review, 9.

[6] Wuhan Geography. Wuhan Press, 2001. 